\title{
Design og udvikling af et intranetbaseret leksikografisk videndelingssystem
}

\section{Indledning}

Denne korte artikel er udarbejdet på basis af (Simonsen 2002b) samt mit arbejde med TeleLex-projektet, jf. (Simonsen 2001a og Simonsen 2001b), og den præsenterer de teoretiske og udviklingsmæssige overvejelser i forbindelse med design og udvikling af et intranetbaseret leksikografisk videndelingssystem i TDC A/S. Det følgende afsnit introducerer de overordnede forskningsmæssige teser i erhvervsforskerprojektet.

Jeg konstaterede for det første hurtigt, at det leksikografiske problem i TDC krævede nye teoretiske og praktiske løsninger. De hidtidige fagleksikografiske overvejelser og løsninger slog slet ikke til, og selvom både (Tarp 1992), (Bergenholtz et al. 1994) og især (Pedersen 1995) diskuterer koncernfagleksikografi, var det helt påkrævet at udvikle nye overvejelser og løsninger, som i særlig grad tager højde for og er baseret på de særlige mekanismer, som findes i intranetbaseret koncernfagleksikografi. Til forskel fra hidtidig praksis argumenterer jeg således for en langt mere holistisk, social-konstruktivistisk og interdisciplinær tilgang til de leksikografiske interessenter og til den anvendte teknologi, jf. (Bijker et al. 1987), som argumenterer for en social-konstruktivistisk tilgang til og opfattelse af teknologi og mennesker. Den rolle, som koncernen eller organisationen, forstået som leksikografisk og organisatorisk mikrokosmos, helt naturligt har, er hidtil blevet helt overset i fagleksikografien. Jeg hævder således, at intranetbaserede leksikografiske artefakter i en koncern eller organisation klart adskiller sig fra konventionelle leksiko-

* Henrik Kфhler Simonsen

Otto Mallings Gade 6, 3.th.

DK-2100 København Ø

www.telelex.dk 
grafiske artefakter, som er beregnet for offentligheden, jf. (Simonsen 2002a), og at der på dette område hidtil har været et forskningsmæssigt hul.

Jeg hævder desuden også, at den hidtidige brugertilgang lader meget tilbage at $\emptyset$ nske, og at der er et stort behov for en langt højere grad af brugerinvolvering og -indflydelse i fagleksikografien. Dette skyldes, at fagleksikografien hidtil ikke i tilstrækkelig grad har tilpasset sig til brugernes virkelighed, jf. i øvrigt (Hausmann 1989), som allerede i 1989 påpegede behovet for tilpasning af leksikografien til det omgivende samfund. En langt mere aktiv brugerinvolvering og -indflydelse er desuden en helt naturlig konsekvens af den nye teknologiske ramme samt af vidensamfundet i øvrigt, og brugerinvolvering og-indflydelse er i særlig høj grad en nødvendighed i intranetbaseret koncernfagleksikografi, hvor koncernen udgør et selvstændigt leksikografisk mikrokosmos. Den hidtidige tilgang til brugeren har således på mange måder været særdeles mangelfuld, idet der indtil nu kun har været fokuseret på selve ordbogen og dens funktioner, men underligt nok ikke på de involverede interessenter.

Ovenstående sammenfattes i denne tese: "Der er i fagleksikografien et stort behov for yderligere teorier og overvejelser om de leksikografiske interessenter i intranetbaseret koncernfagleksikografi”.

Jeg konstaterede for det andet også hurtigt, at fagleksikografien helt manglede teoretiske overvejelser om Intranet/Internet som leksikografisk medium og i særdeleshed helt konkrete overvejelser om og anvisninger på, hvordan intranetbaserede leksikografiske videndelingssystemer skal udvikles og designes inden for rammerne af en koncern eller organisation. Der synes i øvrigt hidtil at have været en stor berøringsangst over for det medium, som vi vel på ingen måder kan kalde nyt længere, og denne berøringsangst har afstedkommet, at der hidtil udelukkende har været anvendt papirbaserede overvejelser og løsninger på et medium, som tilhører en helt anden teknologisk ramme. Denne nye teknologiske ramme og virkelighed, jf. (Simonsen 2002) har som helt naturlig konsekvens, at der skal nye overvejelser og løsninger til, og jeg hævder, at det leksikografiske og tekniske potentiale i Intranet/Internet hidtil slet ikke er blevet udforsket eller udnyttet af hverken den leksikografiske forskningsverden eller af forlagene. Lignende argumenter fremføres af hhv. (Carr 1997), (Storrer/Freese 1997), (Docherty 2000) og især (Harley 2000). 
Ovenstående sammenfattes i følgende tese: "Der er i fagleksikografien et stort behov for teorier og overvejelser om Intranet/Internet som leksikografisk medium og i særdeleshed om udvikling og design af intranetbaserede leksikografiske videndelingssystemer i koncerner og organisationer".

Disse to forskningsmæssige teser blev omsat til både teoretiske og udviklingsmæssige forskningsmål, som alle blev nået inden for de afsatte $\emptyset$ konomiske, organisatoriske og tidsmæssige rammer.

\section{Forsknings- og udviklingsmæssige bidrag}

Dette afsnit præsenterer de forsknings- og udviklingsmæssige bidrag og diskuterer kort udvalgte teoretiske overvejelser, modeller og principper fra især (Simonsen 2002b). Formålet med dette afsnit er således at redegøre for den teoretiske og udviklingsmæssige relevans af mit arbejde.

Indledningsvis er det nødvendigt kort at redegøre for den overordnede metodiske tilgang. Den metodiske tilgang kan vel bedst beskrives som interdisciplinær, idet adskillige forskningsgrene har været inddraget, jf. (Simonsen 2002b). Teori og praksis har desuden været indbyrdes afhængige og befordrende faktorer, og de meget væsentlige synergier mellem teori og praksis er blevet udnyttet optimalt. Denne tilgang har haft som konsekvens, at de udviklede teoretiske overvejelser, modeller og principper alle er blevet til på basis af og i snævert samspil med det praktiske udviklingsarbejde med artefakten TeleLex og omvendt.

I det følgende præsenteres to vigtige teoretiske modeller, som understøtter en $\emptyset$ get forståelse af de mekanismer, som kendetegner intranetbaserede leksikografiske artefakter i en koncern eller en organisation, og som understøtter forståelsen af den rolle som artefakten og interessenterne har i forhold til hinanden.

Figur 1 viser de to vigtigste interessenter i intranetbaseret koncernfagleksikografi og viser nødvendigheden af en tostrenget tilgang til og fokus på disse. 
Figur 1. Brugeren og koncernen.

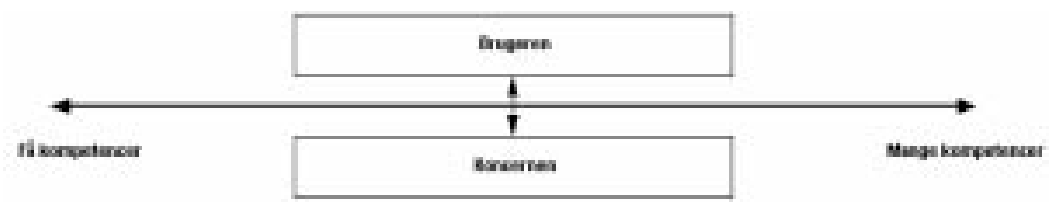

Øverst i figur 1 har vi den individuelle bruger, jf. (Tarp 1992). Den individuelle brugers kompetenceprofil kan placeres langs et kontinuum fra få til mange kompetencer, hvilket jo som bekendt har indflydelse på artefaktens leksikografiske funktioner. Den individuelle brugers leksikografiske behov er funktionsrelaterede og giver sig udslag i de kendte funktioner, som hjælper brugeren med at foretage $\mathbf{L}_{1}$ tekstreception, $\mathbf{L}_{2}$ tekstreception, $L_{1}$ tekstproduktion, $L_{2}$ tekstproduktion, $L_{1}-L_{2}$ oversættelse, $\mathbf{L}_{\mathbf{2}}-\mathbf{L}_{\mathbf{1}}$ oversæattelse og i funktioner, som understøtter tilegnelse af viden om sprog og viden om fag, jf. (Tarp 1992). Som det fremgår af figur 3-10 i Appendiks er TeleLex i høj grad polyfunktionel og brugergrænsefladen kan skræddersys af brugeren i overensstemmelse med dennes kompetenceprofil samt den ønskede funktion.

Nederst i figur 1 har vi koncernen eller organisationen som leksikografisk og organisatorisk mikrokosmos. Koncernens eller organisationens leksikografiske behov kalder jeg funktionalitetsrelaterede, idet de ikke nødvendigvis er bundet til en persons behov, men mere opstår som koncern- eller organisationsrelaterede funktionslignende behov. Koncernens eller organisationens funktionalitetsrelaterede behov giver sig i TeleLex udslag i følgende nyudviklede leksikografiske funktionaliteter, som primært hjælper koncernen eller organisationen med at sikre og forankre leksikografisk videndannelse, leksikografisk videnoverførsel, leksikografisk videndeling, leksikografisk kvalitetssikring og leksikografisk standardisering, jf. (Simonsen 2002B) med henblik på i sidste ende at understøtte koncernens eller organisationens $\varnothing$ nske om at forbedre den interne og eksterne kommunikation for at skabe og fastholde et tilfredsstillende $\varnothing$ konomisk resultat. TeleLex er specielt udviklet til netop at underst $\varnothing$ tte dette, som vurderes at være af stigende forskningsmæssig, organisatorisk og $\varnothing$ konomisk betydning, jf. (Wessel 2001), som diskuterer værdien af leksikografisk og terminologisk videnstyring. 
Figur 1 illustrerer med andre ord, at design og udvikling af intranetbaserede leksikografiske artefakter skal tage højde for to hver for sig lige vigtige og indbyrdes afhængige interessenter: den individuelle bruger og koncernen som leksikografisk mikrokosmos. Begge interessenter stiller krav til den leksikografiske artefakt og uden dette dobbelte fokus vil artefaktens leksikografiske nytteværdi være begrænset for begge parter, jf. (Wiegand 1997), som netop diskuterer nytteværdien af leksikografiske artefakter.

Figur 2 viser en langt mere holistisk, social-konstruktivistisk og interdisciplinær tilgang til og forståelse af interessenterne $\mathrm{i}$ intranetbaseret koncernfagleksikografi og tilblivelsen af den teknologiske artefakt.

Figur 2. En holistisk og social-konstruktivistisk model af intranetbaseret koncernfagleksikografi.

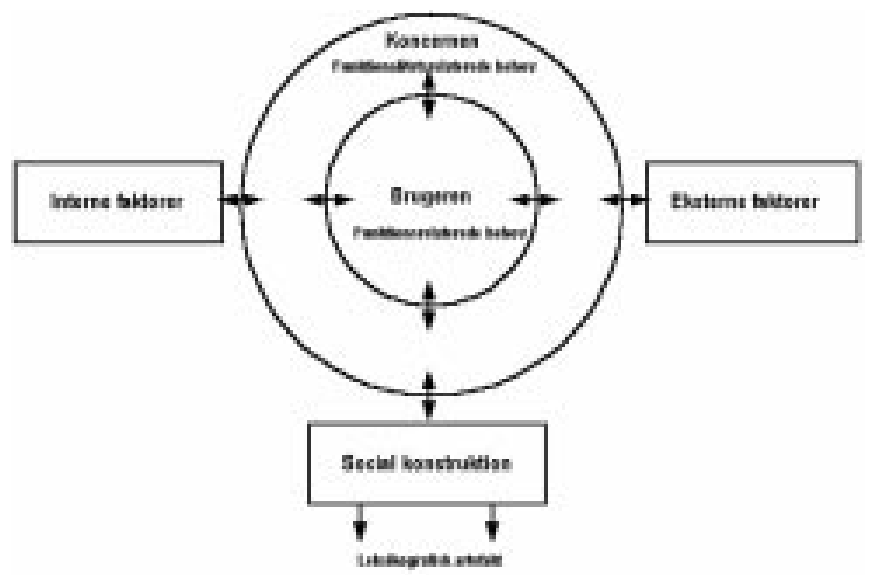

Som det fremgår er den individuelle bruger placeret i centrum af figur 2 . Udenom har vi koncernen som et organisatorisk og leksikografisk mikrokosmos, jf. ovenstående diskussion af de to interessenter. I de to rektangulære kasser på hver sin side af cirklen har vi de interne og eksterne faktorer, som påvirker begge interessenter. De interne faktorer kunne være TDC's officielle sprogpolitik eller TDC's virksomhedskultur. De eksterne faktorer kunne være samfundets krav i form af f.eks. Retskriv- 
ningsordbogen, konkurrenterne eller markedet. Alle disse faktorer, elementer og aktører påvirker hinanden, og det hele munder ud i en særdeles kompleks social konstruktion af selve artefakten TeleLex, jf. bl.a. (Bijker et al. 1987).

Figur 2 viser med andre ord nogle af de vigtige mekanismer, som kendetegner intranetbaseret koncernfagleksikografi, og den sammenfatter nogle af de overvejelser, som man bør gøre sig, når man beskæftiger sig med intranetbaseret koncernfagleksikografi.

På basis af de teoretiske overvejelser udviklede jeg følgende 12 anvendelsesorienterede leksikografiske principper, som bl.a. anviser konkrete forslag til en langt mere vidtrækkende brugertilgang, en betydelig større fokus på den leksikografiske videndelingsproces samt ikke mindst en fokuseret anvendelse af intranettet som leksikografisk medium:

\section{Aktiv brugerinvolvering}

2. Leksikografisk demokrati

3. Leksikografisk videndannelse

4. Leksikografisk videnoverførsel

5. Leksikografisk videndeling

6. Leksikografisk kvalitetssikring

7. Leksikografisk standardisering

8. Leksikografisk delegering

9. Leksikografisk grænsefladetilpasning

\section{Leksikografisk datakonvergens}

\section{Leksikografisk dokumentfangst}

\section{Leksikografisk konkordansfangst.}

Disse 12 anvendelsesorienterede leksikografiske principper fungerede som bindeled mellem de teoretiske modeller og overvejelser og det ITtekniske udviklingsarbejde med TeleLex. Et udvalg af ovenstående leksikografiske principper inddrages og diskuteres kort i det følgende, men en detaljeret gennemgang af disse falder uden for rammerne af denne korte artikel. For en fuldstændig diskussion se (Simonsen 2002b).

Ovenstående teoretiske modeller, overvejelser og anvendelsesorienterede leksikografiske principper udgjorde således det teoretiske og værktøjsmæssige basis for udviklingen af TeleLex, som anses for et væsentligt teoretisk og udviklingsmæssigt bidrag. TeleLex er det eneste system af 
sin art i verden og er et fuldt operationelt intranetbaseret leksikografisk videndelingssystem, som TDC's ca. 19.000 ansatte har adgang til, jf. (Westergaard 2001). TeleLex består bl.a. af en relationel SQL-database, en brugergrænseflade bestående af ca. 75 synlige skærmbilleder, to automatiserede søgeportaler til de to parallelle korpora DANCORP og USCORP, en automatiseret søgeportal til TDC Intranet samt en automatiseret søgeportal til det omgivende Internet via søgemaskinen Google. En tilbundsgående diskussion af TeleLex og dets mange byggedele ligger dog uden for rammerne for denne artikel, hvorfor der henvises til (Simonsen 2002b) for en detaljeret gennemgang.

I Appendiks præsenteres dog 8 udvalgte skærmbilleder fra TeleLex. TeleLex består af to overordnede moduler - et intranetbaseret datavisningsmodul TelePresentor og et intranetbaseret dataredigeringsmodul TeleEditor, som vist i figur 3 og 4 . Hele systemet kaldes TeleLex og har følgende ni valgmuligheder: Dansk-engelsk, Engelsk-dansk, Dansk grammatik, Engelsk grammatik, Forslag, Forum, Information, Links og Sprogpolitik, se også menuen i venstre side af skærmbilledet i figur 5 .

Det hævdes, at det danske søgebillede i figur 5 indeholder en del leksikografiske nyskabelser. For det første kan brugeren her vælge at anvende en konventionel alfabetisk/semasiologisk søgefunktion, en systematisk/ onomasiologisk søgefunktion eller at anvende en kombination af disse. Hermed gives brugeren optimale betingelser for at finde lige netop det lemma, som han leder efter. For det andet er søgebilledet i figur 5 opbygget efter det leksikografiske princip leksikografisk grænsefladetilpasning, som betyder, at brugeren selv kan skræddersy brugergrænsefladen i overensstemmelse med kompetenceprofil og ønsket leksikografisk funktion, se også figur 7-10. Brugeren har altså mulighed for selv at sammenstykke de $\emptyset$ nskede moduler. Det engelske søgebillede i TeleLex fungerer som det danske og er vist i figur 6 .

Figur 8-10 viser artikelvisningsbilledet og som allerede anført ovenfor kan brugeren selv indstille, hvorledes dette artikelvisningsbillede skal se ud allerede i søgebilledet, se også figur 5-6. Standardindstillingen i TeleLex er visning af alle fire moduler, men TeleLex husker brugerens sidste indstillinger således, at han kun skal indstille sine foretrukne søge - og visningskriterier én gang. 
Figur 7 viser modul 1 og 2 i artikelvisningsbilledet. Modul 1 er obligatorisk og indeholder lemma, ækvivalent, udtale, ordklasseangivelse samt morfologi for både lemma og ækvivalent. Der anvendes her konventionelle leksikografiske principper for visning af f.eks. ordklasse og morfologi. Selve udtalen af både det danske lemma og den engelske ækvivalent sker automatisk ved at klikke på det skærmbilledvenlige højtalerikon. Modul 2 indeholder links til illustrationer, encyklopædiske oplysninger samt henvisning(er) til overordnede og sideordnede lemmata. For illustrationer og encyklopædiske informationer har jeg valgt hhv. et kameraikon og et ikon af en lysende pære, hvilket hævdes at være skærmbilledvenlige ikoner. Endelig anvendes en konventionel strukturindikator for henvisninger nemlig en pil. Hvis brugeren klikker på selve henvisningslemmaet springer han automatisk til det pågældende lemma.

Figur 8 viser modul 3 i artikelvisningsbilledet. Her har jeg også valgt skærmbilledvenlige artikelinterne ikoner, f.eks. flagikoner, som angiver danske og engelske sprogbrugseksempler. Modul 3 indeholder autentiske sprogbrugseksempler hentet fra de to underliggende korpora DANCORP og USCORP. Modul 3 indeholder desuden synonymangivelser på både dansk og engelsk samt kollokationsangivelser, som er markeret vha. en sort trekant.

Figur 9 viser modul 4 i artikelvisningsbilledet. Modul 4 hævdes at være en væsentlig leksikografisk nyskabelse baseret på det leksikografiske princip leksikografisk datakonvergens, som indebærer, at adskillige leksikografiske og ikke-leksikografiske datakilder konvergeres til gavn for de leksikografiske interessenter. I modul 4 kan brugeren således foretage en automatisk og struktureret søgning i de to korpora ved at klikke på hhv. det røde og blå computerikon, han kan foretage en automatisk og struktureret søgning efter det danske lemma på hhv. internettet og intranettet ved at klikke på de danske links, og han kan ligeledes søge efter de(n) engelske ækvivalent(er) på hhv. internettet og intranettet ved at klikke på de engelske links.

Hermed nyder brugeren godt af princippet leksikografisk datakonvergens, $o g$ han skal ikke bruge unødig tid på at skifte mellem forskellige applikationer, ligesom han kan være sikker på til stadighed at have adgang til dynamiske og opdaterede leksikografiske data, hvilket jo også sikres af redigeringsmodulet TelePresentor. 
Figur 10 viser forslagsfunktionen i TeleLex. Forslagsfunktionen er den ene af tre muligheder, som leksikografen og brugerne har for at interagere og dermed sikre leksikografisk videndannelse, leksikografisk videnoverførsel og leksikografisk videndeling. Disse leksikografiske funktionaliteter er desuden tæt forbundet med det leksikografiske princip leksikografisk demokrati, som sikrer en struktureret og aktiv involvering af den kompetente bruger, jf. i øvrigt Simonsen (2002c). Ved hjælp af forslagsfunktionen i TeleLex kan brugerne således indsende forslag til optagelse af nye lemmata i TeleLex, hvormed den leksikografiske videndelingsproces er tilvejebragt.

\section{Konklusion}

Sammenfattende hævder jeg, at mit arbejde med design og udvikling af et intranetbaseret leksikografisk videndelingssystem i TDC A/S har resulteret $\mathrm{i}$ væsentlige teoretiske og udviklingsmæssige bidrag til den fagleksikografiske forskning. Som vist ovenfor udgøres det samlede forskningsog udviklingsmæssige bidrag af en række teoretiske modeller, overvejelser og principper for intranetbaseret koncernfagleksikografi samt ikke mindst et antal helt konkrete anvisninger på, hvorledes et intranetbaseret leksikografisk videndelingssystem udvikles, designes og forankres i en koncern eller organisation. Jeg hævder således afslutningsvis, at mit arbejde kan anvendes af fremtidige koncernleksikografer i forbindelse med lignende projekter.

Se også www.telelex.dk for at få adgang til yderligere information om TeleLex-projektet.

\section{Bibliografi}

Bergenholtz, Henning et al. (1994). Manual i fagleksikografi. Udarbejdelse af fagordbøger - problemer og løsningsforslag. Med bidrag af: Grete Duvå, Anna-Lise Laursen, Hans Kristian Mikkelsen, Sandro Nielsen, Ole Norling-Christensen og Jette Pedersen. Herning, Systime.

Bijker, Wiebe E., Hughes, Thomas P., Pinch, Trevor J. (1987). The Social Construction of Technological Systems. New Directions in the Sociology and History of Technology. The MIT Press, Cambridge, Massachusetts, 17-28, 28-50, 159-187.

Carr, Michael (1997). Internet Dictionaries and Lexicography. In International Journal of Lexicography 10, 209-230. 
Docherty, Vincent, J. (2000). Dictionaries on the Internet: An Overview. In Proceedings of The Ninth EURALEX International Congress, 8 - 12 August 2000, Universität Stuttgart, Volume I, 67-74.

Harley, Andrew (2000). Software Demonstration: Cambridge Dictionaries Online. In Proceedings of The Ninth EURALEX International Congress, 8 - 12 August 2000, Universität Stuttgart, Volume I, 85-88.

Hausmann, Franz Josef (1989). Die gesellschaftlichen Aufgaben der Lexikographie in Geschichte und Gegenwart. In Franz Josef Hausmann/Oskar Reichmann/Herbert Ernst Wiegand/Ladislav Zgusta: Wörterbücher, Dictionaries, Dictionaires. An International Encyclopedia of Lexicography, First Volume 1989. Berlin/New York: Walter de Gruyter, 1-18.

Pedersen, Jette (1995). Koncernspecifik brancheordbog med sarligt henblik på teknisk engelsk. Prakonceptuelle overvejelser og koncept. Ph.d.-afhandling. Århus, Handelshøjskolen i Århus.

Simonsen, Henrik Køhler (2000a). Papirordbogen er død. Længe leve computerordbogen! In MDTnyt nr. 3, 2000, 19-35.

Simonsen, Henrik Køhler (2000b). Report on the Design, Development and Compilation of a bilingual multifunctional Intranet-based Convergence Telecom Lexinome at a major Danish Telecom Group. In Proceedings of The Ninth EURALEX International Congress, 8 - 12 August 2000, Universität Stuttgart, Volume I, 89-96.

Simonsen, Henrik Køhler (2001a). TeleLex - A Lexicographic Knowledge Management System: An Analysis of the Social Construction and Business Economic Potential of TeleLex. ATV Business Report. Danish Academy of Technical Sciences, Aarhus School of Business and TDC A/S, 1-43.

Simonsen, Henrik Køhler (2001b). Teoretiske overvejelser om Internet-baseret koncernfagleksikografi. In Nordiske studier i leksikografi 7. Rapport fra Konference om leksikografi i Norden. Farøerne 21.-26. august 2001. Thórshavn: Nordisk forening for leksikografi 2001 (I trykken).

Simonsen, Henrik Køhler (2002a). Corporate LSP Intranet Lexicography. In Proceedings of The Tenth EURALEX International Congress, 13 - 17 August 2002, University of Copenhagen (I trykken).

Simonsen, Henrik Køhler (2002b). TeleLex: Theoretical Considerations on Corporate LSP Intranet Lexicography: Design and Development of TeleLex - an Intranet-based Lexicographic Knowledge and Communications Management System. PhD Thesis, 436 pages. Aarhus School of Business, Denmark.

Simonsen, Henrik Køhler (2002c). User Involvement in Corporate LSP Intranet Lexicography. In Proceedings of Eleventh International Symposium on Lexicography, 2-4 May 2002, University of Copenhagen (I trykken).

Storrer, Angelika/Freese, Katrin (1997). Wörterbücher im Internet. In Deutsche Sprache 1996/2, 97-153. 
Tarp, Sven (1992). Prolegomena til teknisk ordbog. Ph.D. dissertation. Århus: Spansk Institut. Handelshøjskolen i Århus, 1-173.

Wiegand, Herbert Ernst (1997). Über die gesellschaftliche Verantwortung der wissenschaftlichen Lexikographie. In Hermes, Journal of Linguistics no. 18 - 1997, 177202.

Wessel, Lene (2001). Sproget sælger varen. In IngeniфrenNet, fredag 2. februar 2001.

Westergaard, Astrid (2001). TeleLex giver translatøren mere tid til kreativt arbejde. In Sprog \& Erhverv, januar 2001, nr. 1, 16-17. 
5. Appendiks

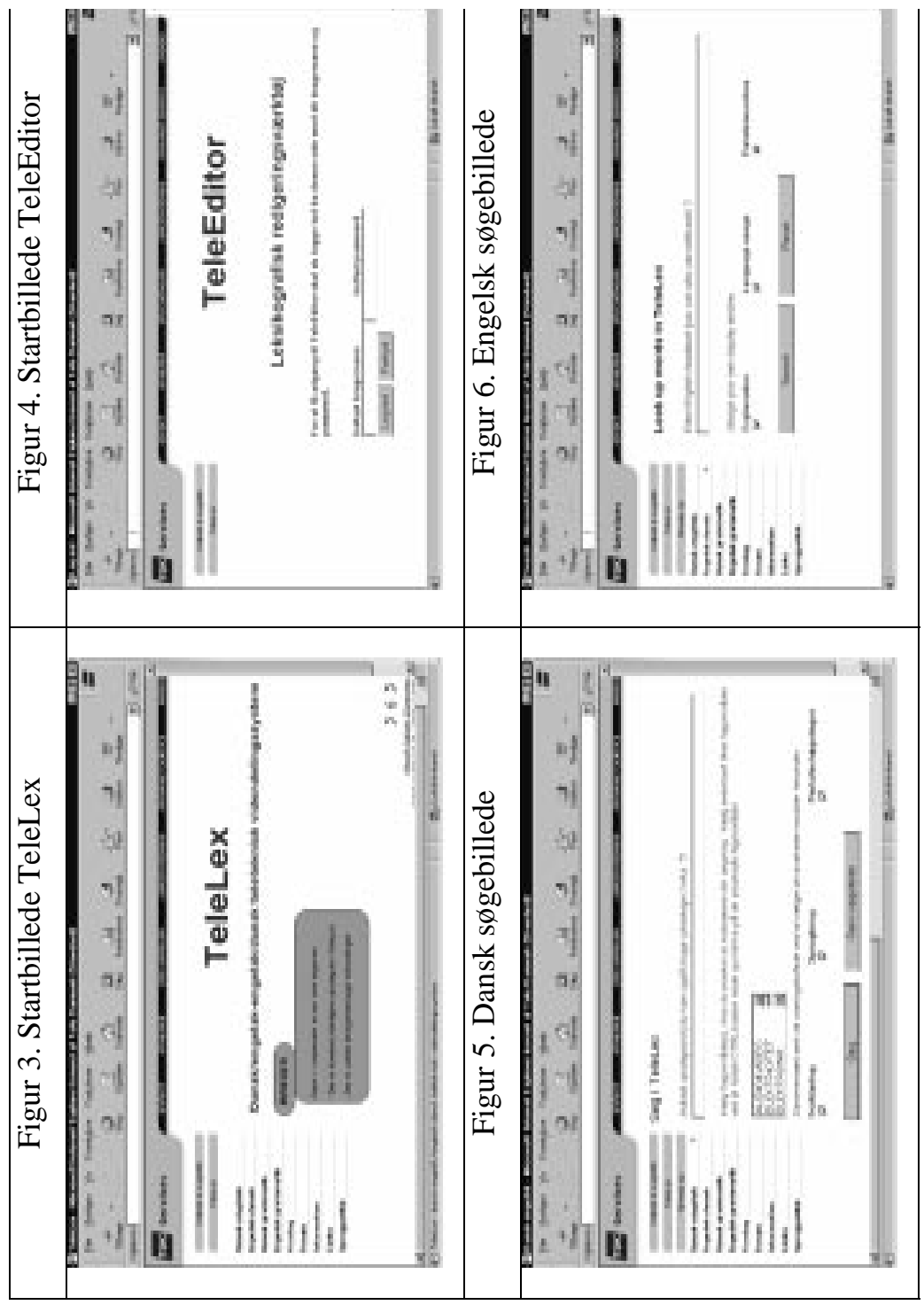




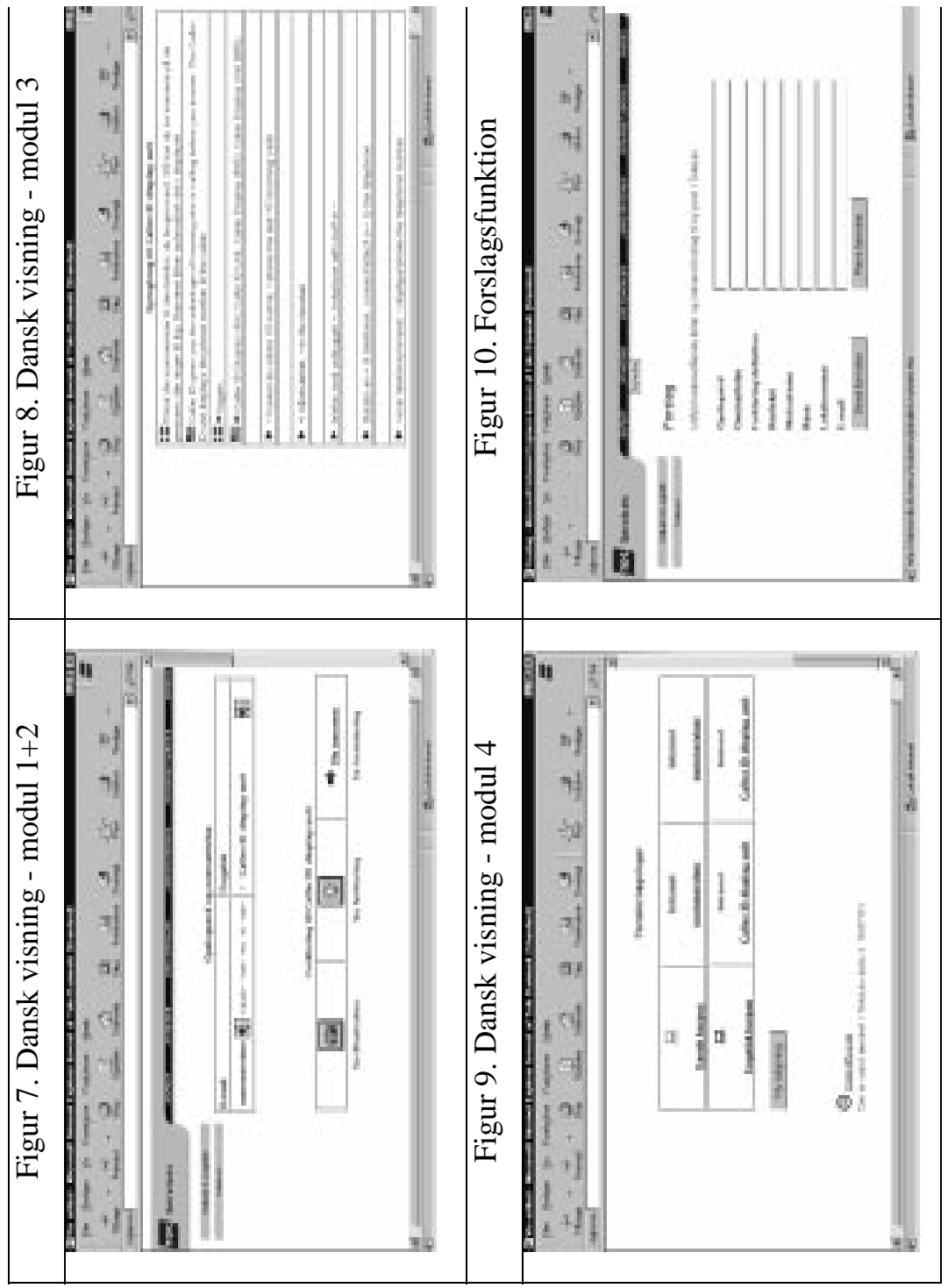


